\title{
ANÁLISE DA QUEBRA DA ESTRIA DA LUVA DESLIZANTE DA ARVORE DE TRANSMISSÃO ENTRE EIXO*
}

\author{
Cristian Deiner Dutra ${ }^{1}$ \\ José Dimas de Arruda² \\ Edilberto da Silva Souza ${ }^{2}$ \\ José Sebastião dos Reis Silva ${ }^{2}$ \\ Cássio Roberto de Araújoº \\ Leandro Lopes Hermsdorff ${ }^{3}$ \\ Mauricio Vieira ${ }^{4}$ \\ Nilo Antunes Ferreira ${ }^{4}$ \\ Alexandre Mágno Franco Ferreira ${ }^{4}$
}

\section{Resumo \\ O desgaste dos metais afetam diretamente os componentes de um eixo de transmissão cardan. Este estudo analisou o desgaste apresentado pelo eixo cardan em contato com a luva interna e externa, até o momento da fratura. A análise da região fraturada se deu por imagens metalográfica geradas pelo Microscópio Eletrônico de Varredura (MEV); e a análise química pelo sistema Espectrometria de Energia Dispersiva de Raios-X (EDS), contida também no MEV. Observou-se pela micrografia, uma fratura caracterizada pelo desgaste, agravada pelo esforço em fadiga. A análise química detectou ausência de importantes elementos químicos em aços com aplicações em desgaste. \\ Palavras-chave: Eixo Cardan; Desgaste; Fadiga; MEV. \\ ANALYSIS OF THE TRANSIENT TREAD SLIP SLEEVE STRETCH ANALYSIS BETWEEN AXIS}

\section{Abstract}

The wear of metals directly affects the components of a drive shaft. This study analyzed the wear presented by the cardan shaft in contact with the internal and external glove until the moment of the fracture. The analysis of the fractured region was by metallographic images generated by the Scanning Electron Microscope (SEM); And the chemical analysis by the X-ray Dispersive Energy Spectrometry (EDS) system, also contained in the SEM. It was observed by the micrograph, a fracture characterized by the wear, aggravated by the effort in fatigue. The chemical analysis detected absence of important chemical elements in steels with wear applications.

Keywords: Cardan Shaft; Wear; Fatigue; MEV.

1 Graduando em Engenharia Mecânica, Fundação Presidente Antônio Carlos, Conselheiro Lafaiete, Minas Gerais, Brasil.

2 Engenheiro, Mestre, Professor da Fundação Presidente Antônio Carlos, Conselheiro Lafaiete, Minas Gerais, Brasil.

3 Bacharel em Física, Mestre, Professor da Fundação Presidente Antônio Carlos, Conselheiro Lafaiete, Minas Gerais, Brasil.

4 Engenheiro, Professor da Fundação Presidente Antônio Carlos, Conselheiro Lafaiete, Minas Gerais, Brasil 


\section{INTRODUÇÃO}

De acordo com Weihermann ${ }^{12}$, a função do eixo cardan (eixo de transmissão) resume-se na transmissão da energia que é produzida pelo motor para o eixo diferencial, e, consequentemente é transferida para as rodas. Macedo ${ }^{4}$, afirma que se trata de um conjunto de componentes mecânicos que transmite o torque e a rotação produzidos pelo motor para o eixo diferencial do veículo, compensando as diferenças angulares e de comprimento entre eles por meio de juntas universais. Zaupa $^{13}$ afirma que os dois eixos tubulares que formam o eixo cardan são classificados como sendo um primário, localizado na fonte motriz e um secundário que se encontra ao centro do eixo de tração. A Figura 1 destaca 0 eixo de transmissão Cardan.

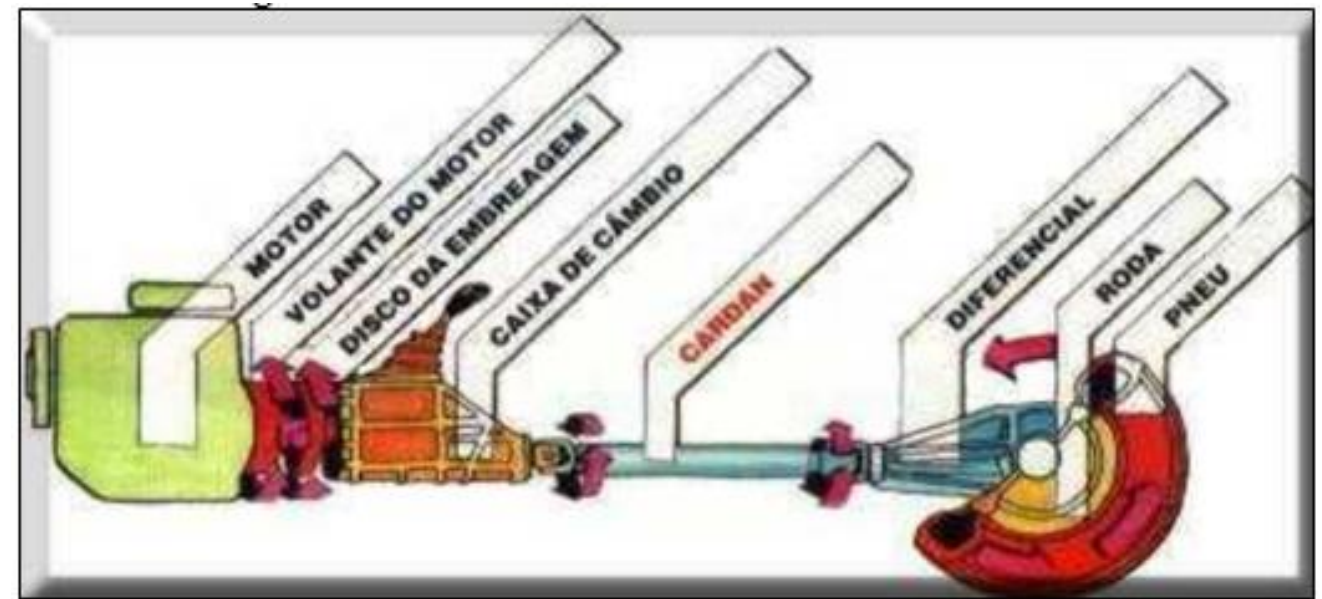

Figura 1 - Eixo de transmissão ou eixo cardan ligando o motor ás rodas. (Macedo ${ }^{4}$ )

A eficácia do eixo cardan se dá em relação ao deslocamento realizado do centro de gravidade dos veículos para os eixos traseiros e dianteiros, possibilitando maior energia e equilíbrio em relação à tração realizada. Sua função depende de outros componentes como a luva interna (Figura 2a) ou externa (Figura 2b). A luva é um equipamento básico do cardan e se apresenta como função a transmissão de torque ou movimento, afirma Macedo 4 .

A luva interna localiza-se entre os conjuntos extremos de um eixo cardan, chamados de juntas universais, promovendo um deslizamento axial, enquanto a luva externa localiza-se na extremidade do cardan, acoplada à transmissão ou caixa de câmbio.
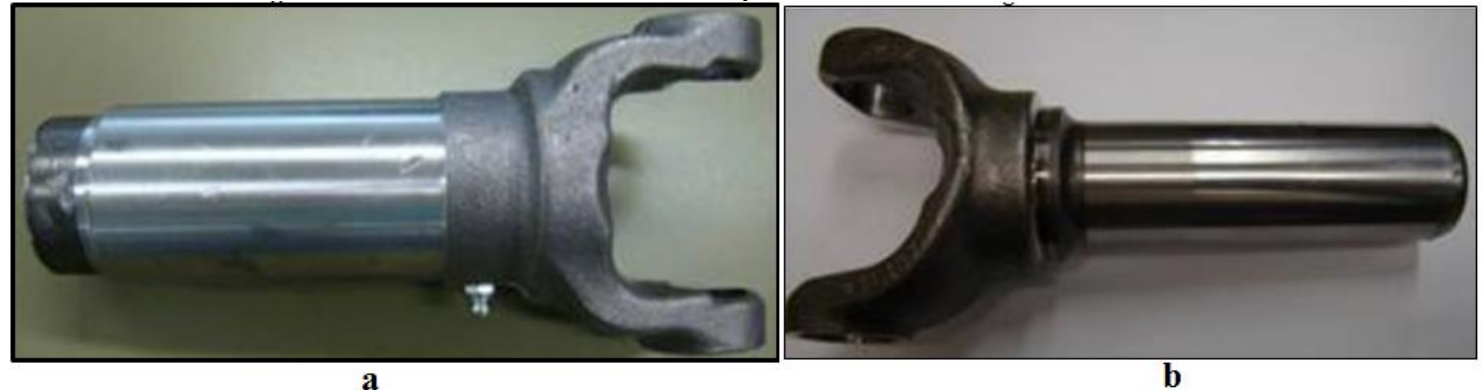

Figura 3 - a) Luva interna do eixo cardan; b) Luva externa do eixo cardan. (Macedo ${ }^{4}$ )

Segundo Radi ${ }^{8}$, o desgaste de metais pode ser compreendido como sendo a perda de material resultante ao movimento que é realizado entre duas superfícies por meio de ações mecânicas. Os diferentes tipos de desgastes em metais são relacionados às suas características mecânicas, divididos em desgaste adesivo, abrasivo, por fadiga e corrosivo, como mostrado na Figura 3 . Machado ${ }^{5}$ afirma que os fatores que 
explicam a presença de desgaste em metais são composição química, módulo de elasticidade, dureza, condutividade térmica, geometria da peça, carregamento aplicado, contaminação, umidade, lubrificação e presença ou ausência de desgaste interno.

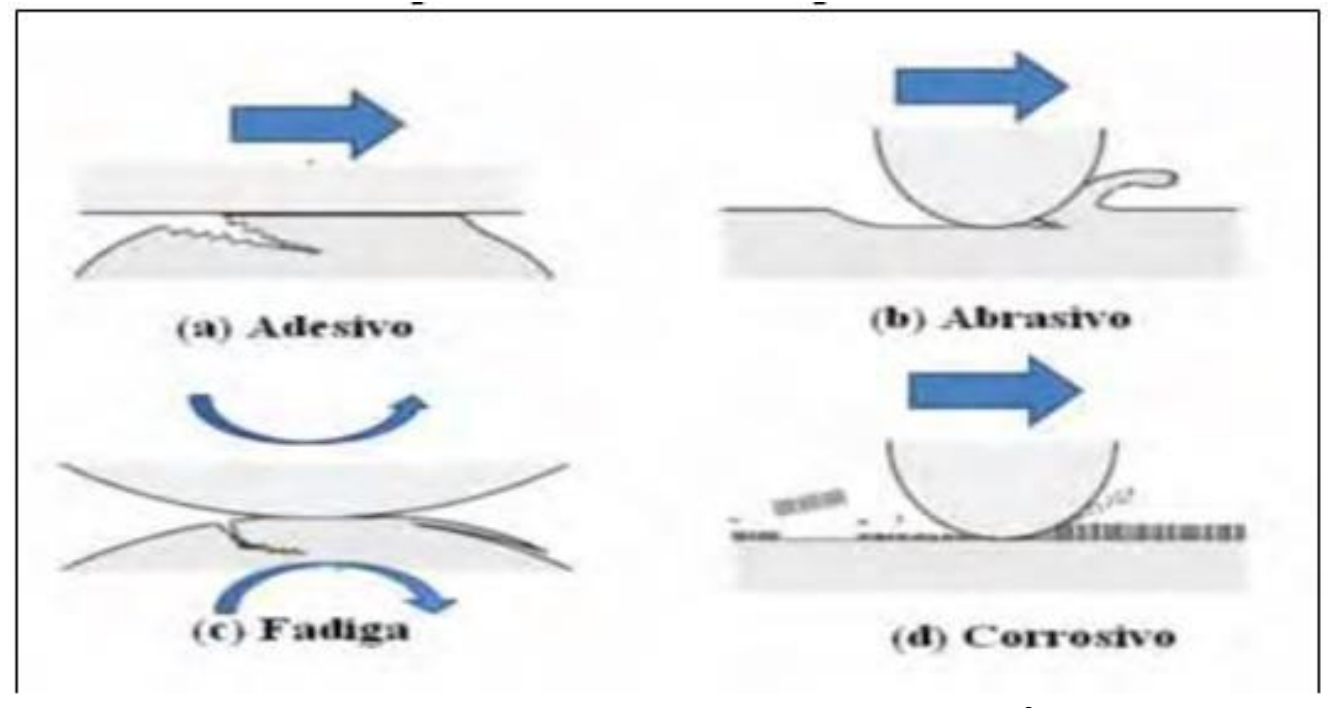

Figura 3 - Tipos de desgaste em metais. $\left(\operatorname{Radi}^{8}\right)$

O desgaste adesivo ocorre com a perda de materiais na superfície de uma ou mais peças que estão em contato mecânico. Este desgaste provoca o rompimento do material, levando a perda de suas características, apresentando escorregamento, que pode levar à fratura do material.

O desgaste abrasivo é a perda de material provocado pelo movimento entre duas ou mais superfícies diretamente. De acordo com Machado ${ }^{5}$, existem três categorias de abrasão: por riscamento ou a baixas tensões, que é resultante do deslizamento de partículas livres sobre a superfície do componente, moagem ou altas tensões, em que o material é forçado a passar entre duas superfícies recebendo altas tensões dinâmicas, provocando 0 desgaste das superfícies e comprometendo 0 equipamento, além de goivagem ou sulcamento, no qual a superfície do metal apresenta-se geralmente macia e com cortes, resultantes do impacto e da compressão da tensão dinâmica.

O desgaste corrosivo é a interação mecânica referente ao escorregamento que interage quimicamente com a superfície, para que o funcionamento da peça seja satisfatório, faz-se necessário que ocorra a raspagem da superfície, o que danifica o metal, provocando o desgaste, afirma Machado ${ }^{5}$. Leite ${ }^{3}$ ressalta que um equipamento com desgaste corrosivo deve ser monitorado e avaliado constantemente, pois a interação com a superfície do metal promove danos que podem evoluir para perda da peça em razão da constante retirada do material químico que se encontra durante o seu funcionamento.

Segundo Radi $^{8}$, o desgaste por fadiga apresenta-se como resultante do carregamento dinâmico que é produzido em razão do acúmulo de tensão e deformações plásticas levando ao surgimento de trincas que danificam significativamente a composição da peça, bem como o seu funcionamento. Para Leite $^{3}$ o desgaste por fadiga leva ao surgimento de trincas e fissuras, que danifica 0 equipamento, levando a ruptura do material após um número de ciclos de carregamento.

Segundo Malcher ${ }^{6}$, a fadiga apresenta-se como sendo um fenômeno que ocorre quando um componente mecânico, submetido a carregamentos dinâmicos, sofre 
degradação e falha sob a ação de tensões menores que sua resistência estática. As falhas por fadiga são ocasionadas devido à tensão exercida sobre uma estrutura por ultrapassar o limite elástico dos cristais, o que agrava consideravelmente a condição dos metais por ampliar os esforços cíclicos, que resulta em trincas que levam a fratura do equipamento. A fratura por fadiga não surge integralmente, apresenta-se como sendo o desgaste gradual da peça devido à tensão dinâmica e que se agrava mediante aos esforços que são efetuados para o seu funcionamento, agravando a peça de forma a levar a sua quebra.

Para Arcanjo ${ }^{2}$, a ruptura por fadiga é resultante da nucleação e propagação de trincas de maneira gradativa que surgem no material devido a tensões cíclicas dinâmicas. Além de danificar as estruturas metálicas, o processo de fadiga acarreta prejuízos econômicos, devido à necessidade de paralisação dos equipamentos nas empresas, o que influencia no processo produtivo podendo comprometer 0 cumprimento da demanda da organização em razão do tempo de parada para a substituição das peças que apresentam danificações.

Uma forma de evitar desgastes dos materiais e paralizações é aplicando a manutenção preventiva, em que manter o cuidado com a lubrificação é essencial. A lubrificação dos equipamentos trata-se de uma estratégia fundamental para a melhoria do seu desempenho e redução dos desgastes dos metais em decorrência das tensões que são aplicadas para a realização de suas atividades. O uso de óleos lubrificantes é uma medida que retarda o desgaste das peças por não permitir o atrito direto entre os metais evitando danos como o surgimento de trincas que levam à ruptura do equipamento, afirma Almeida ${ }^{1}$.

De acordo com Teófilo $^{10}$, os métodos utilizados na caracterização dos tipos de fraturas em um material são variados, permitindo relacionar as propriedades químicas, físicas e metalúrgicas do material para melhor conhecimento da relação causa/efeito da falha.

A análise química para qualificar e quantificar os componentes presentes num material pode ser feita por via úmida ou instrumental. Para detectar motivos de falha, as análises químicas instrumental são mais utilizadas. As técnicas de caracterização instrumental em sua maioria se baseiam na excitação atômica por uma fonte energética, fornecendo resultados quantitativos e qualitativos através da detecção desses átomos por emissão ou absorção, diz Ratti ${ }^{9}$.

Moraes $^{7}$ afirma que a análise metalúrgica do material pode ser feita macro e microscopicamente. A análise macroscópica é superficial, mas de extrema importância para uma primeira determinação da existência de trinca e uma possível falha. Para Teófilo $^{10}$, a análise microscópica pode ser dividida em análise microestrutural morfológica da superfície fraturada e análise metalográfica do material.

Segundo Moraes 7 , o Microscópio Eletrônico de Varredura (MEV) tem grande aplicação nesta análise, pois sua resolução fornece imagens da superfície das fraturas mais claramente. Através desse equipamento pode-se fazer a análise metalográfica, identificando a microestrutura do material, análise microscópica na região da falha, observando o tipo de fratura ocorrida no material, além de ser possível uma análise química se o equipamento contiver, por exemplo, sistemas EDS (Espectrometria de Energia Dispersiva de Raios-X) ou WDS (Detecção de comprimento de ondas por Raios-X). 


\section{MATERIAIS E MÉTODOS}

A pesquisa realizada foi embasada em um estudo exploratório qualitativo do estudo de caso com o intuito de analisar os fatores que levaram a quebra da estria da luva deslizante da árvore de transmissão entre eixo. Caracterizou-se por ser um estudo exploratório descritivo, com visão de deescrever os efeitos da deformação por meio da análise metalográfica através do Microscópio Eletrônico de Varredura (MEV).

O procedimento proposto para o estudo configurou uma análise da possibilidade de eliminação de quebra prematura das estrias da luva deslizante da árvore de transmissão entre diferenciais nos veículos $6 \times 4$ Tractor equipados com eixo trativo Meritor, através da identificação do aço utilizado para a produção deste equipamento.

A luva deslizante externa apresenta desgaste prematuro nos dentes de contato com o eixo interno, como mostrado na Figura 4. Este desgaste ocorre devido o esforço cíclico que é aplicado no equipamento, acarretando consequentes deformações de fadiga, tanto na luva externa quanto no eixo interno. Observam-se pequenas trincas que comprometem a estrutura do material.

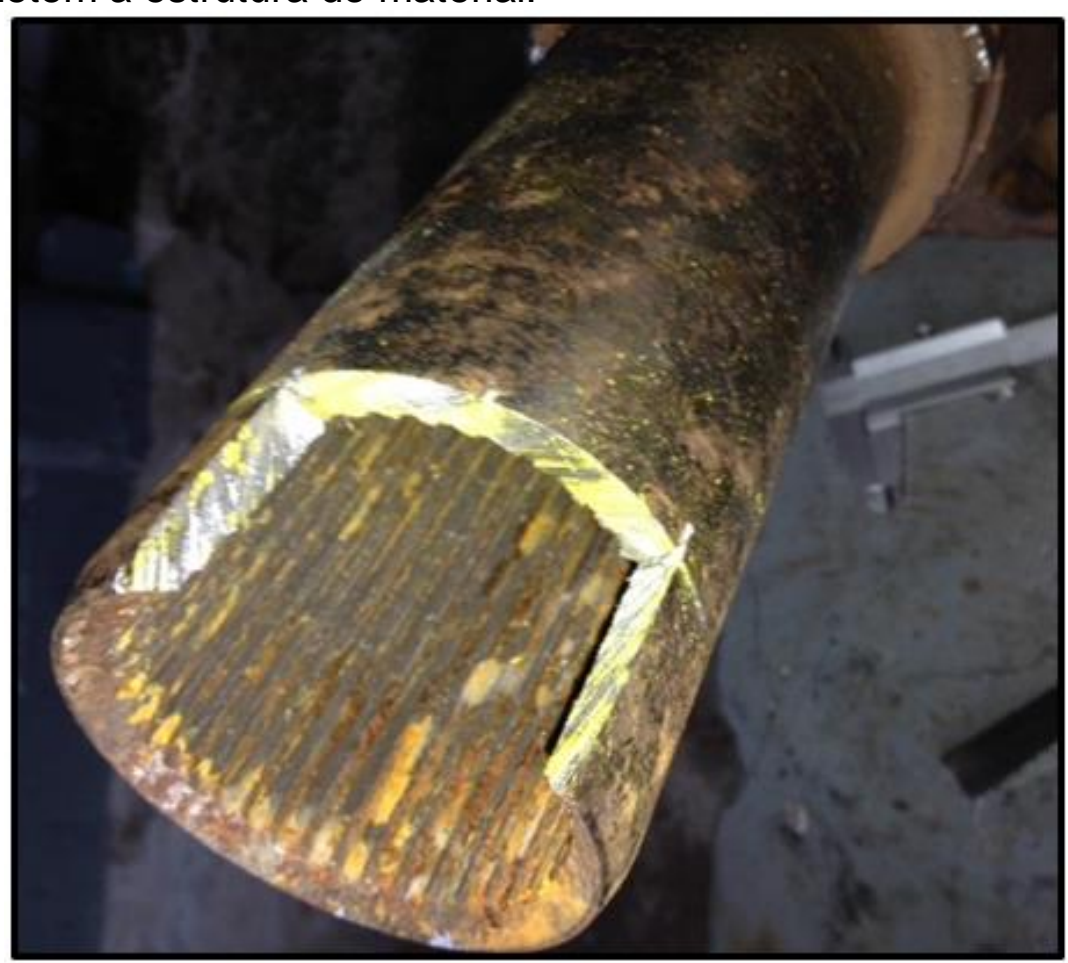

Figura 4 - Eixo Cardan utilizado na pesquisa.

A Figura 5 são amostras do eixo interno (à esquerda) e parte da luva externa (à direita), retiradas do material para realização da análise metalográfica e química no Microscópio Eletrônico de Varredura (MEV). 

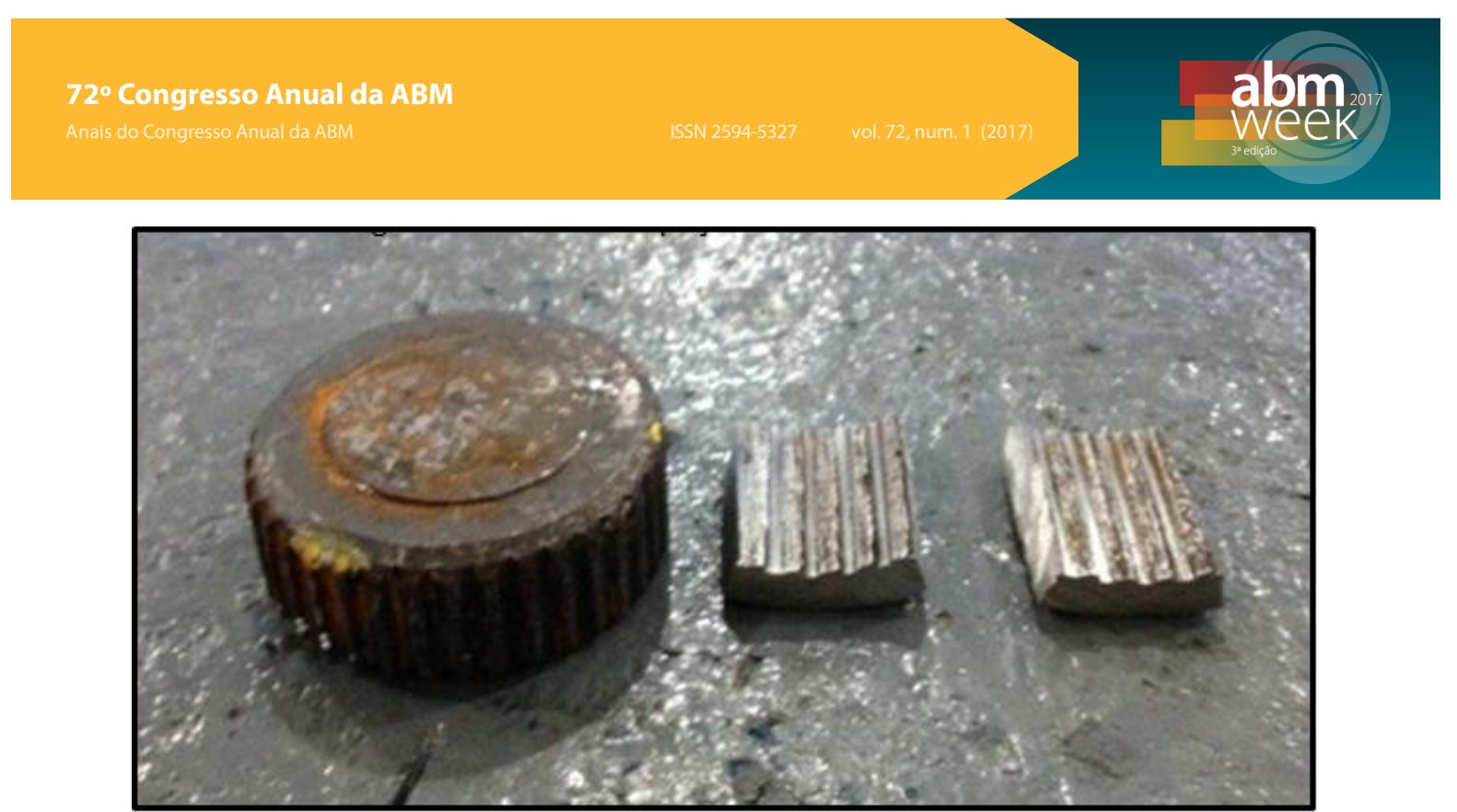

Figura 5 - Amostras do material. Corpo de prova do eixo interno e da luva externa.

O microscópio eletrônico de varredura utilizado para análise do material foi a Tescan Vega 3, mostrado na Figura 6. A série Vega foi projetada visando uma ampla gama de aplicações e necessidades nas pesquisas e nas indústrias. Este modelo oferece aos seus usuários vantagens da tecnologia de ponta, tais como a obtenção de imagens eletrônicas de alto desempenho, um sistema de varredura ultrarrápido com compensação para as aberrações de imagem estática e dinâmica e ferramenta de scripting para aplicações definidas pelo usuário. Além disso, o equipamento possui os sistemas EDS, WDS e EBDS que permitem a realização de uma análise química do material.

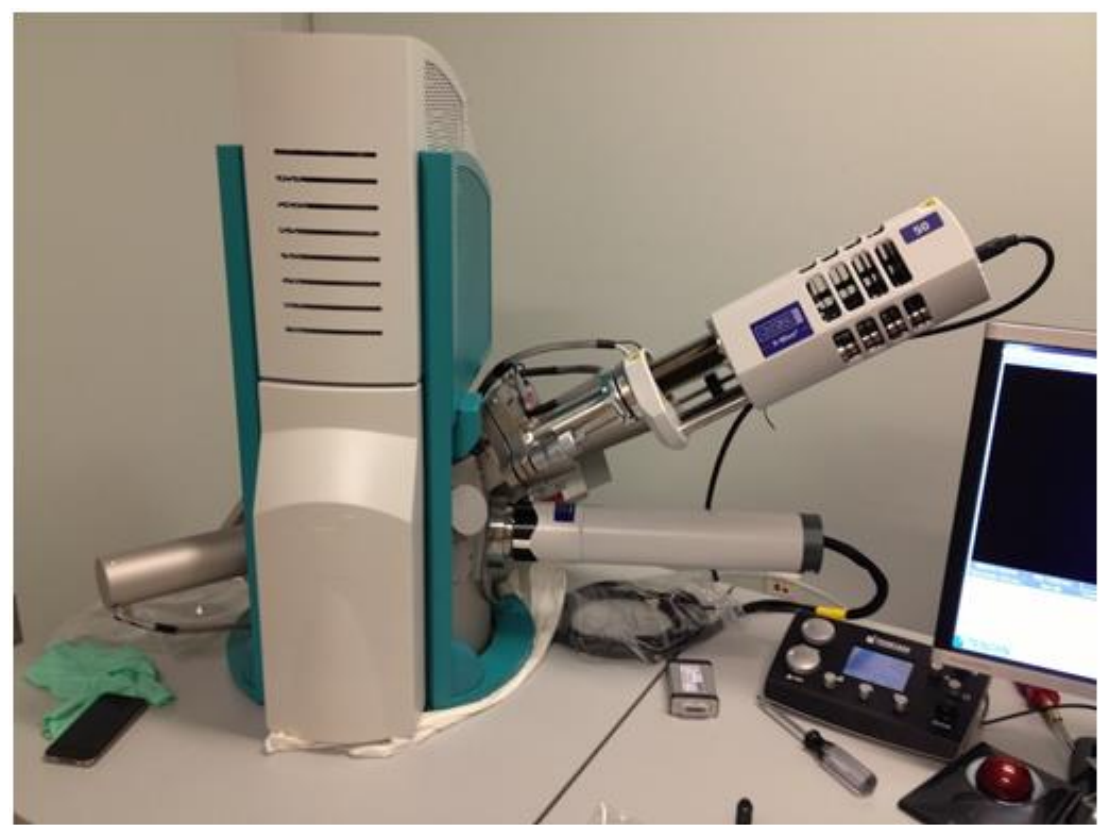

Figura 6 - Imagem de um Microscópio Vegas 3. (Site Tescan do Brasil ${ }^{11}$ ) 


\section{RESULTADOS E DISCUSSÃO}

A Figura 7a mostra a seção do eixo interno na vista frontal da superfície do dente em que ocorre a fratura. Observa-se pela análise metalográfica a ocorrência de deformação plástica com perda do volume do material. A Figura $7 \mathrm{~b}$ mostra a fratura dúctil do eixo interno do material, com um aumento que destaca o local da fratura. Ambas as imagens foram obtidas pelo MEV.
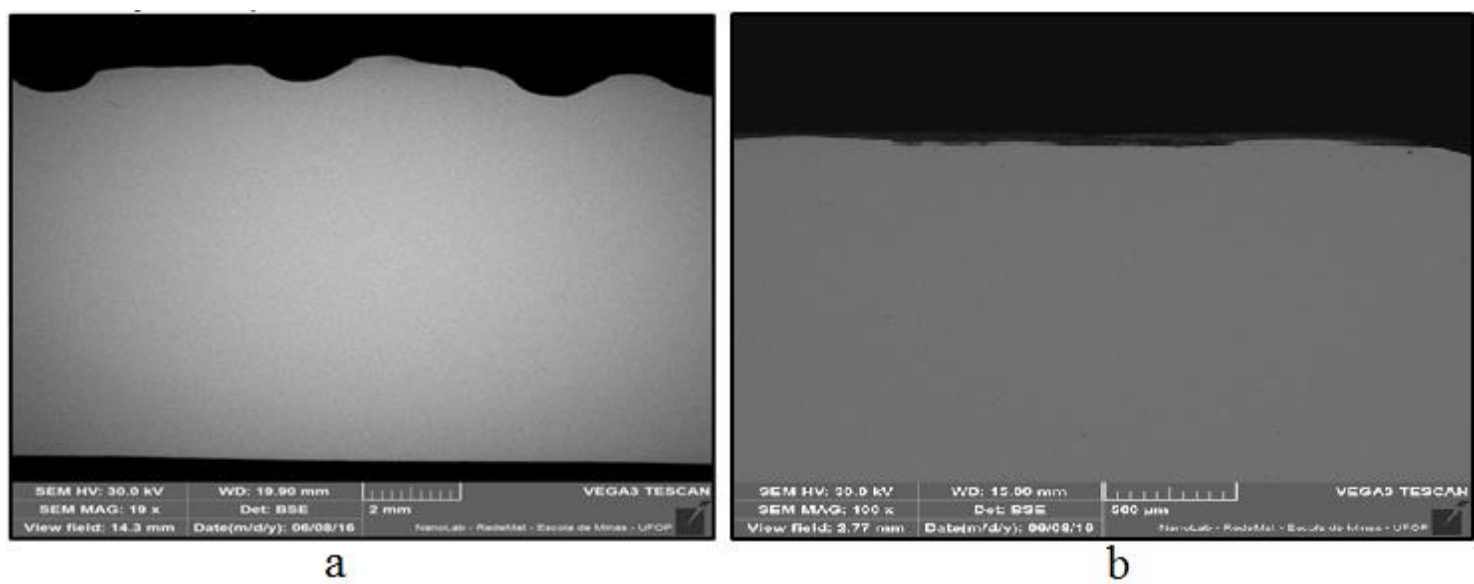

Figura 7 - a) Seção do eixo mostrando a fratura nos dentes do eixo, b) Seção do eixo onde ocorre a fratura do material.

A análise no local da fratura do material é mostrada na Figura 8a, obtida pelo microscópio eletrônico de varredura. A deformação plástica observada no material qualifica uma fratura dúctil do material. A Figura 8b é uma ampliação da área fraturada que destaca a fratura dúctil do material.

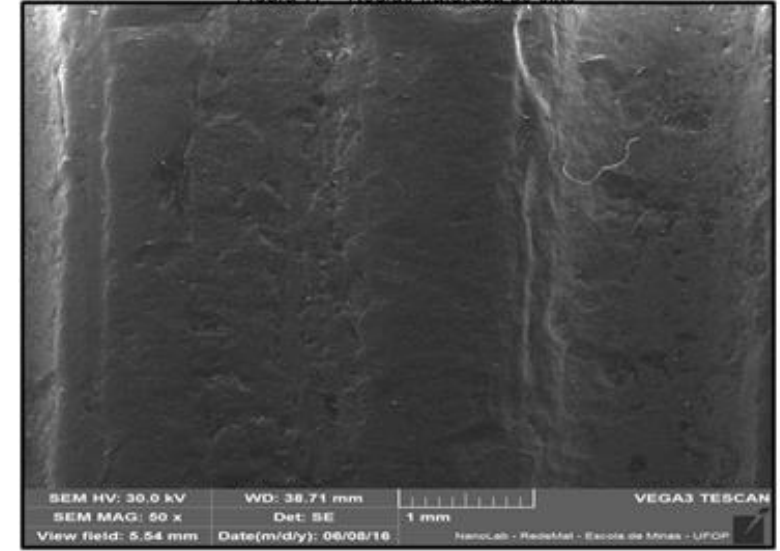

a

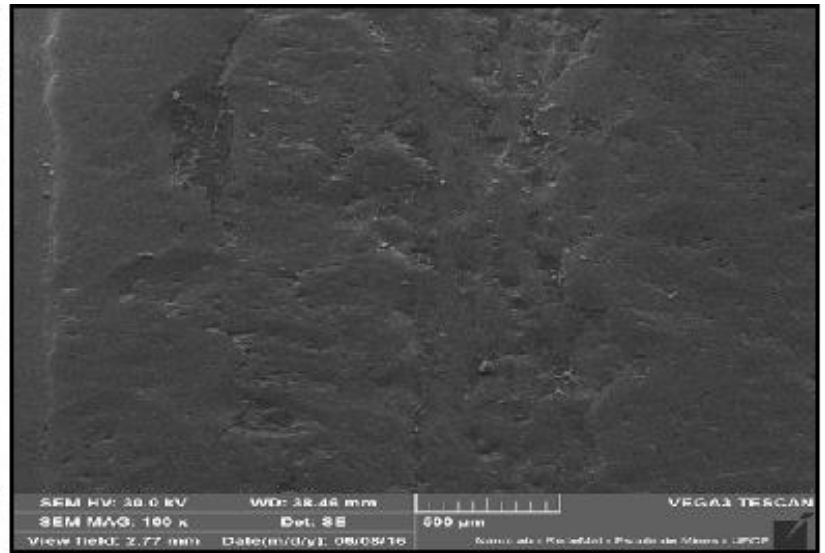

b

Figura 8 - a) Imagem no local da fratura do material com aumento de 40x. b) Imagem no local da fratura do material com aumento de 100x.

A Figura 9a mostra a presença de trincas da amostra analisada, na direção normal do eixo no dente. A trinca presente na amostra pode ser detalhada na Figura 9b, formada longitudinalmente em direção ao eixo. 


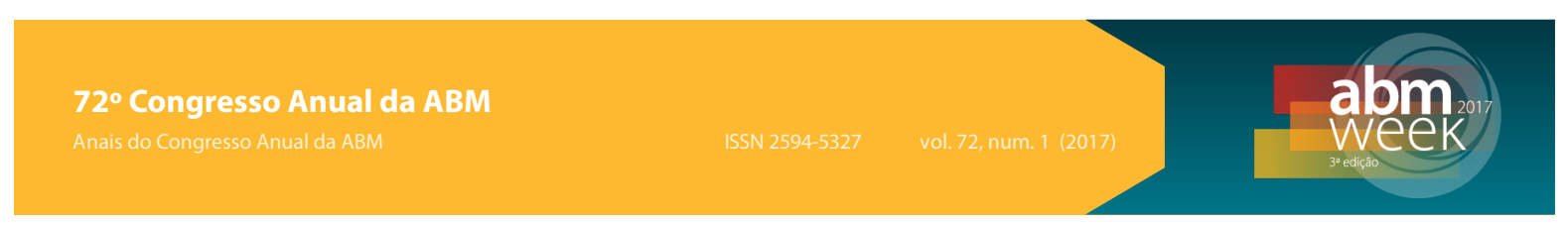

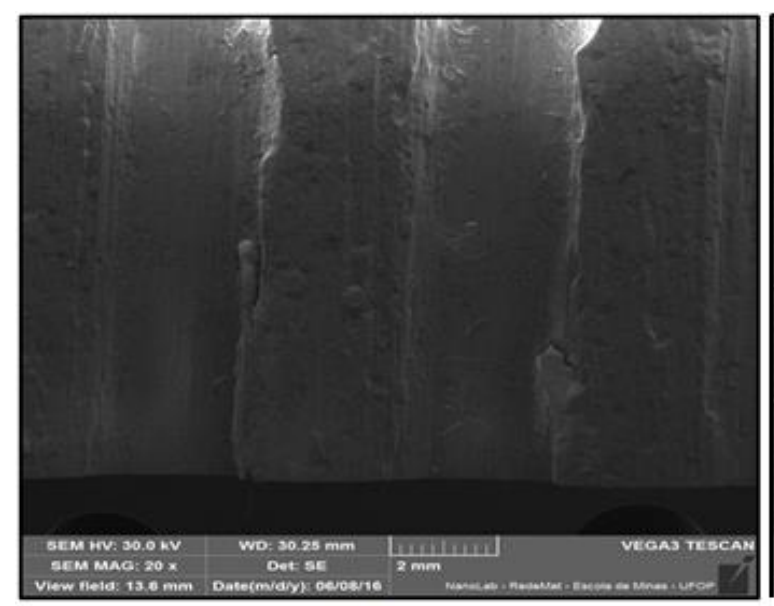

a

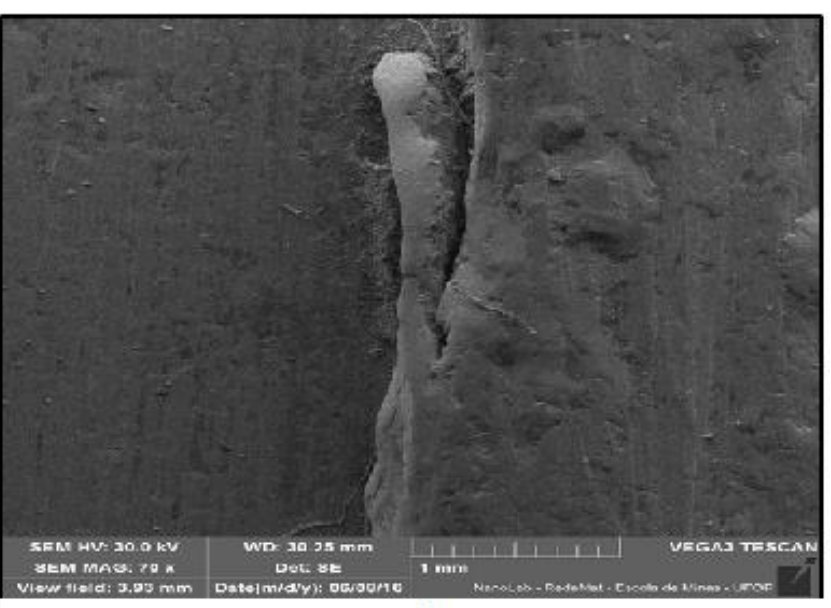

b

Figura 9 - a) Imagem microestrutural da região da fratura longitudinal no dente do eixo Cardan com aumento de 20x; b) Imagem microestrutural no local da trinca no dente do eixo Cardan com aumento de 70x.

As trincas formadas longitudinalmente caracterizam desgaste entre os dentes da luva que levaram o material a uma fratura dúctil, isto pode ser observado na Figura 10a. A Figura 10b é uma imagem microestrutural do material, identificada como uma microestrutura martensítica.

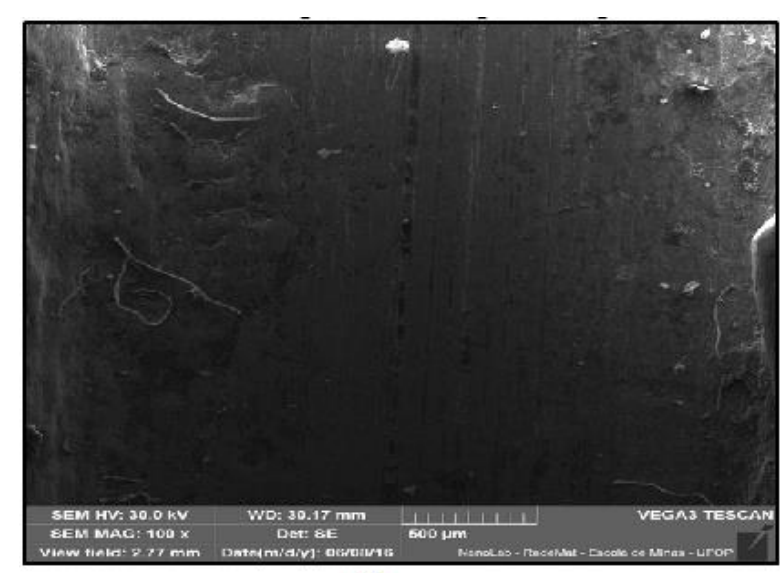

a

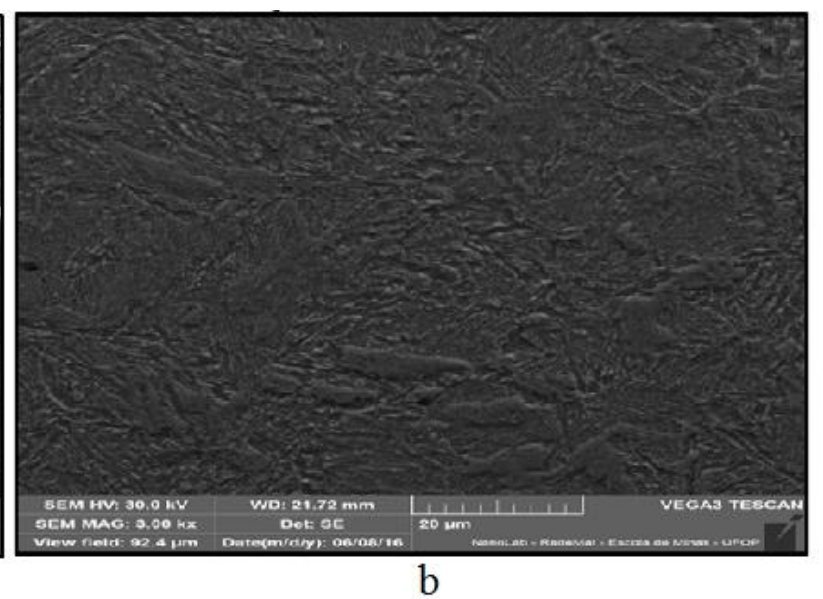

b

Figura 10 - a) Microestrutura com aumento de 100x detalhando a trinca longitudinal no dente do eixo cardan; b) Identificação da microestrutura martensítica do aço utilizado no eixo cardan.

Com a necessidade de verificar a composição química do material utilizado na construção do eixo cardan analisado, foi realizada uma análise EDS (Espectrometria de Energia Dispersiva de Raios-X) utilizando o mesmo Microscópio Eletrônico de varredura $(\mathrm{MEV})$. Esta análise foi realizada em três pontos do eixo cardan, identificando a porcentagem dos principais elementos químicos presentes no aço utilizado para a construção do eixo. A Figura 11 é uma imagem microestrutural dos três locais de análise química do eixo cardan. 


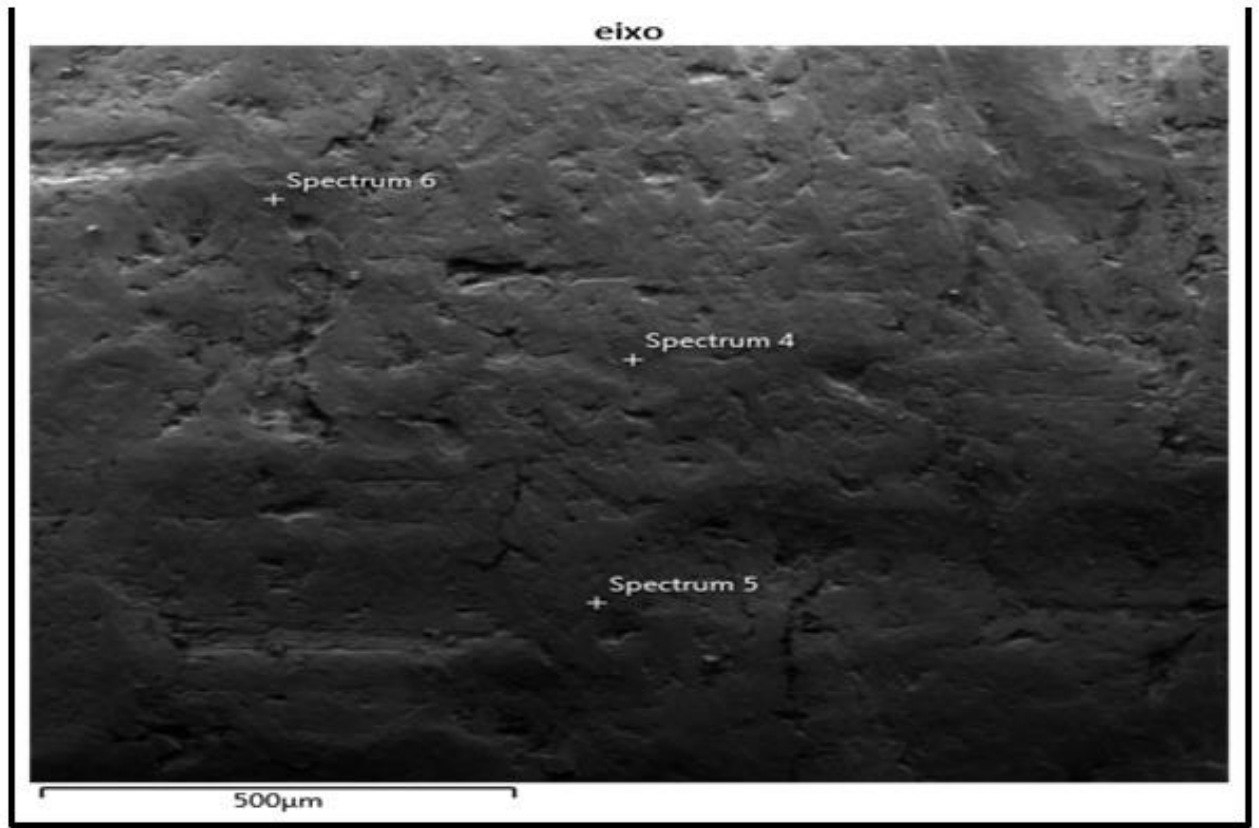

Figura 11 - Região do eixo cardan utilizado na análise de Espectrometria de Energia Dispersiva de Raios-X - EDS.

A análise EDS identificou os principais componentes químicos presentes no eixo cardan. As Figuras 12, 13 e 14 são resultados da espectrometria de cada um dos três pontos analisados.

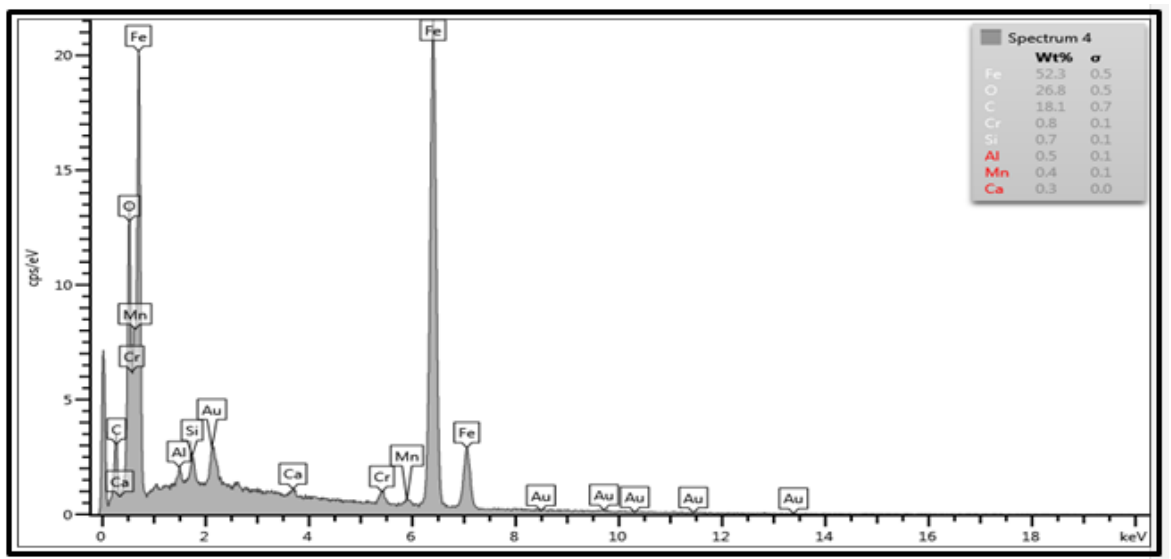

Figura 12 - Componentes químicos presentes no eixo cardan determinado via EDS no primeiro ponto de análise.

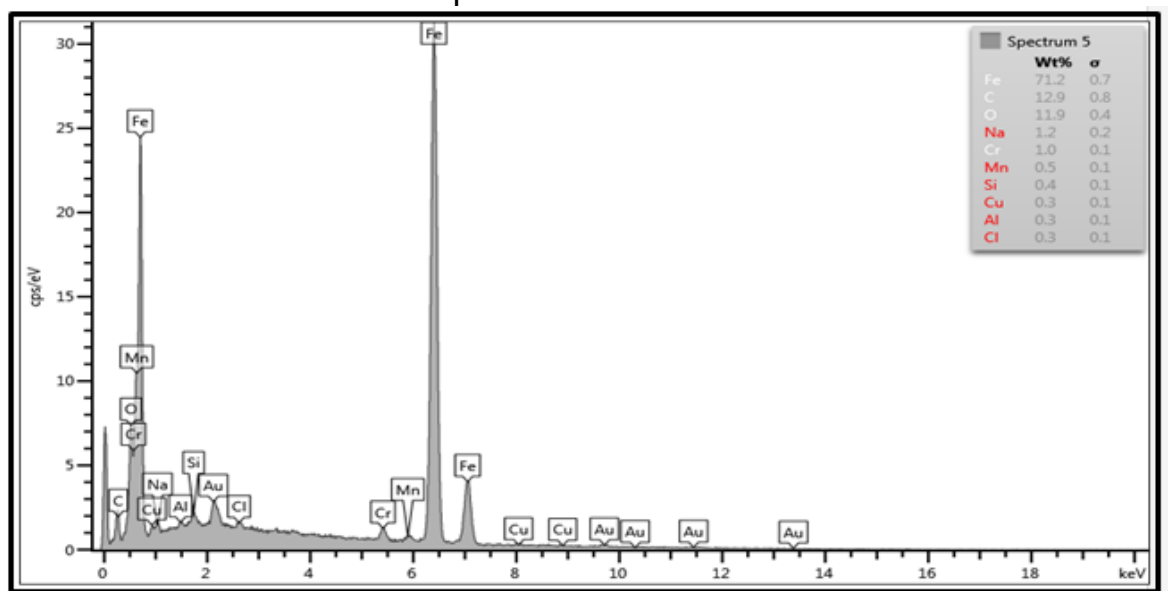

Figura 13 - Componentes químicos presentes no eixo cardan determinado via EDS no segundo ponto de análise. 


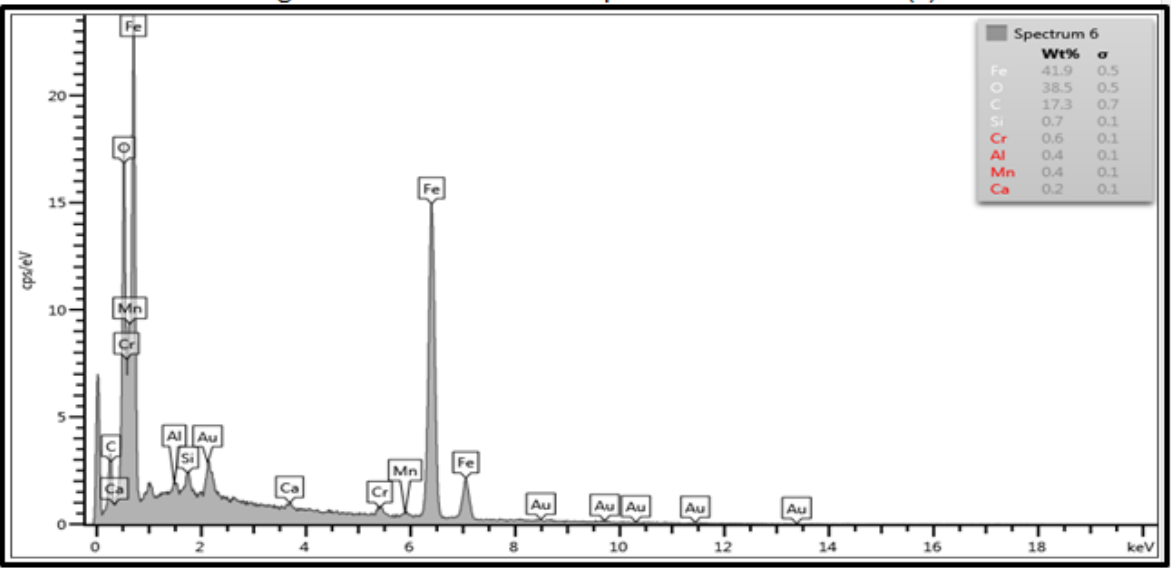

Figura 14 - Componentes químicos presentes no eixo cardan determinado via EDS no terceiro ponto de análise.

Uma análise global dos três espectros permitiu concluir que o aço analisado possui fundamentalmente os elementos Ferro, Carbono, Oxigênio, Silício e Cromo, além da presença de sódio no segundo espectro. A presença de oxigênio em todas as análises permite concluir que o material apresentava um percentual de porosidade que pode ter sido fundamental na fratura precoce do eixo. O sódio identificado em apenas um dos pontos de análise pode ser identificado como uma impureza pontual, considerando que este não é um elemento usualmente presente na estrutura dos aços. Impurezas favorecem também a fragilização do material.

Os demais elementos presentes no material, Ferro, Carbono, Silício e Cromo, quando comparado à série de aços ABNT, e levando em conta a aplicação de cada aço, é um aço com composição química próxima do aço 4320, muito utilizado na fabricação de engrenagens, pinhões, pinos e componentes de máquinas onde há exigência de dureza superficial obtida pelo processo de cementação. Porém, a análise química não identifica os elementos Níquel e Molibdênio, que fazem parte desse aço ABNT 4320 como apresentado na Figura 15 que compara a composição química com o aço em análise.

\begin{tabular}{|c|c|c|c|c|c|c|c|c|}
\hline $\begin{array}{l}\text { ABNT } \\
\text { SAE }\end{array}$ & C & $\mathrm{Mn}$ & $\begin{array}{l}\mathrm{P} \\
\text { máx. }\end{array}$ & $\begin{array}{l}\mathrm{S} \\
\text { máx. }\end{array}$ & Si & $\mathrm{Ni}$ & $\mathrm{Cr}$ & Mo \\
\hline \multirow{2}{*}{4320} & 0,17 & $-0,45$ & \multirow{2}{*}{0,035} & \multirow{2}{*}{0,040} & 0,15 & $-1,65$ & $-0,40$ & $-0,20$ \\
\hline & 0,22 & 0,65 & & & 0,35 & 2,00 & 0,60 & 0,30 \\
\hline $\begin{array}{l}\text { Eixo } \\
\text { Cardan }\end{array}$ & C & Mn & $\begin{array}{l}P \\
\text { máx. }\end{array}$ & $\begin{array}{c}\text { S } \\
\text { máx. }\end{array}$ & $\mathrm{Si}$ & $\mathrm{Ni}$ & $\mathrm{Cr}$ & Mo \\
\hline EDS & 0,18 & 0,40 & & & 0,70 & & 0,60 & \\
\hline
\end{tabular}

Figura 15 - Comparação da composição química obtida via análise EDS do eixo cardan e do Aço ABNT4320.

A aplicação mecânica do eixo cardan exige resistência a altas temperaturas e ao desgaste devido ao alto atrito/fricção que este material é submetido. Elementos de liga como Níquel e Molibdênio são fundamentais para o material ter uma vida útil longa. Portanto, a ruptura do material estudado foi acelerada pela aplicação de um aço que não tinha composição química ideal para a aplicação que foi submetida. 


\section{CONCLUSÃO}

Os resultados permitem inferir que:

- O eixo cardan em estudo apresentou fragilidade devido ao alto desgaste dessa ferramenta que trabalha constantemente em atrito. Este desgaste pode ser diminuído com melhor lubrificação entre as peças em contato.

- As análises metalográfica realizadas pelo MEV possibilitou a identificação de trincas longitudinais no material, causadas por desgaste devido ao atrito dos componentes. A fratura apresentou deformação plástica, caracterizando comportamento dúctil.

- A análise EDS permitiu a identificação da composição química do eixo cardan, que comparado ao aço ABNT 4320, resistente ao desgaste, apresentou ausência de elementos de liga como níquel e molibdênio, fundamentais para a aplicação de materiais que trabalham em fricção.

\section{Agradecimentos}

Ao Laboratório de Microscopia Eletrônica e Microanálise da REDEMAT (Nanolab) pela obtenção das microscopias utilizadas neste trabalho, em especial ao Me. Ney Pinheiro Sampaio por todo apoio fornecido.

\section{REFERÊNCIAS}

1 ALMEIDA, A.A.M. Análise da situação atual da gestão de óleos lubrificantes usados. Trabalho de licenciatura, Universidade Eduardo Mondlane, 2011.

2 ARCANJO, E.P. Caracterização do comportamento à fadiga de molas. Dissertação de Mestrado. Engenharia Mecânica. Instituto Superior Técnico. Universidade Técnica de Lisboa. Lisboa, 2008.

3 LEITE, R.V.M. Estudo comparativo entre ligas resistentes ao desgaste abrasivo, aplicadas por soldagem, em chapas metálicas para fabricação de placas antidesgaste. Dissertação de Mestrado. Universidade Federal de Minas Gerais, UFMG, Belo Horizonte, Mg, 2008.

4 MACEDO, C.V. Análise da influência dos parâmetros de retificação cilíndrica na rugosidade média $(\mathrm{Ra})$ da luva externa para eixo cardan. Monografia, Escola de Engenharia da Universidade Federal do Rio Grande do Sul, Porto Alegre, RS, 2012.

5 MACHADO, J.M.O. Análise de falhas em martelos oscilantes dos desfibradores da Indústria Sucroalcooleira da Região Norte-Nordeste. Dissertação de Mestrado. Universidade Federal do Rio Grande do Norte, Natal, 2008.

6 MALCHER, L. Um modelo para determinação da resistência à fadiga multiaxial para carregamentos de flexão e torção combinados, fora de fase e com amplitude constante com base no critério do invariante do tensor. Dissertação de Mestrado em Ciências Mecânicas. Universidade de Brasília, Brasília, DF, 2006.

7 MORAES, W.A.; TAVARES, M.M.; FARIAS, E.S.A. Análise de Falhas - Parte 4: Início de Análise de Falhas. Siderurgia Brasil, v.15, n.105, 2014.

8 RADI, P. A. Estudos de fenômenos tribológicos em materiais carbonosos. Tese de Mestrado. Instituto Tecnológico de Aeronáutica. São José dos Campos, SP, 2008. 
9 RATTI, G. Técnicas de análise química de compostos inorgânicos. Apostila. PMI2201, 2000.

10 TEÓFILO, J. Estrutura e Propriedades dos Materiais. Ensaios Mecânicos dos Materiais. Apostila, Capítulo 9, 2010.

11 Tescan do Brasil [página da internet], São Bernardo do Campo, SP, Brasil, [acesso em 15 de out. de 2016]. Disponível em: http://www.tescan.com/br.

12 WEIHERMANN, H.W. Estudo sobre aplicação de transmissão continuamente variável para veículos de pequeno porte. Trabalho de Conclusão de Curso. Universidade Federal de Santa Catarina. Curso de Engenharia Automotiva. Joinville, SC, 2015.

13 ZAUPA C. O que é o Eixo Cardan? Conheça sua função e suas principais aplicações. 2015. 